\title{
The Application of Big Data in Marketing
}

\author{
Manwen Lü ${ }^{a}$, Guochao Lin',** \\ Fuzhou University of International Studies and Trade, Fuzhou, Fujian, China \\ a61822151@qq.com, b521138739@qq.com
}

Keywords: Big data, marketing, customer insight

\begin{abstract}
With vast amounts of data available and accessible, marketers focused on gathering and exploiting data for further advantages. The volume of data is growing at exponential rate. The decision response to data is faster than ever before. Today's market phenomenon requires data to be utilized appropriately and efficiently. A lot of companies pursue after advanced technology and analytical methods of big data to take full advantage of what data takes along. 4Ps and customer behavior prediction are beneficial from the applications of big data. It allows marketers to have a better customer insights and predict customer behavior thus executes "precision marketing” for firm a competitive advantage. In the phenomenon of the increasing prevalence of internet and digital devices, big data are also has its own management challenges including privacy and security issues.
\end{abstract}

\section{Introduction}

Recent technological developments urge the emergence of big data that is enabling us to gain more data much faster than ever before. Data-science techniques based on big data. With the help of advanced big data analyzing technologies, insights can be better gained to improve business strategies. Data offers customer behavioral insights that are translated into market advantage by marketers. Moreover, businessmen can read the potential needs of customers thus predict customers' behavior. Erevelles et al. mentioned that big data is often used to extract the hidden insights about customer behavior [1]. With the adaptive and dynamic capabilities, insights disclose from big data make great contribution for value creation[2]. Big data has been regarded as Digital Oil because of so much value with it [3]. It is also called as the New Raw Material of the $21^{\text {st }}$ century [4]. In order to enhance their competitive advantage, companies in almost every industry are exploiting data [5]. Committing to capture and create data asset and developing data mining as a key strategic component is the primary reason for "Digital 100" companies such as Facebook and Twitter having such high valuation in the worldwide context [6]. Following with that, big-data analytical thinking hits the road. Sivarajah classified big data analytical methods into three types, descriptive analytics for understanding "what happened in the business", predictive analytics for anticipating "what is likely to happen in the future, "and prescriptive analytics for responding "so what "and "so now" [7]. These analytical methods support for making decisions and organizing everything right. Kambatla announced that the most visible application of big-data analytical has been in business enterprises, and a retailer's operating margin can be increased by $60 \%$ by utilizing the data analytics [8]. From the research of Brynjolfsson, Hitt and Kim, there is strong evidence that depends on big data, business performance can be improved [9]. Therefore, it is an unavoidable 
trend to drive entrepreneurs to pay much attention into the application of big data.

\section{The Application of Big Data in 4Ps}

The article focus on the application of big data in marketing. Rich and current data enables marketing executives make better decision based on evidence rather than on intuition. A lot of researches proved that big data have done a great job on creating value in marketing. 4Ps is a classic theoretical framework for marketing, and the application of big data now is staged in these four terms. In terms of product, marketers are empowered ability of responding to competition via upgrading products without time wasting. For example, to overcome the fierce competition from Hyundai, Skoda, and Tata who are relatively competitors, Ford Motor utilized big data to make a revolution in product innovation and design. Ford collects consumer data from its vehicles on the road through sensor and remote app-management software. Satell said Ford facilitates product innovation through using big data rather than waiting for insights from traditional marketing research [10].

On pricing side, the organizations master customers 'willingness to pay. Take ticket price of baseball games as an example, the majority of league baseball have frequently pricing the ticket based on big data to improve revenue management. Besides the rate and timing of ticket sales, weather, construction around the ball park, teams on the raise, the potential for record-setting event, fever of chatter about a game in social media are integrated into big data analysis for setting the ticket prices.

In the matter of promotion, the insightful information from big data helps marketers having a better understanding of customers 'needs. The utilization of big data contributes to improve the effectiveness of existing marketing activities. Google is a typical company putting big data to good use. Google determines whether an advertising displayed on a customer's smartphone by combining a customer's location information and search history. Therefore, the insightful information from big data enables advertisers to better measure the effectiveness of of advertising. Based on the effectiveness of previous advertising, marketers can develop next promotion strategies. Story suggested that a firm should take advantage of customer insights from big data to redefine its marketing activities for bringing radical innovation into force [11]. Enable by modern technological applications and location-based services, firms can use location information to get insightful information for improving their promotion strategy and select target customers.

Place also benefits from big data. Amazon obtains tremendous value from their big data. Amazon analyses the data including order history, product search history and shopping cart activities to predict the time of a customer purchasing a certain product and begins shipping the product to the nearest warehouse before the customer submits the order online. Amazon uses insights from big data to recreate distribution strategy. It is essential for organizations to make good use of big data.

\section{Big Data for Customer Insights}

Researchers and marketing practitioners focus more energy on what they know. However, Erevelles announced that "understanding what we do now know, referred to as ignorance" [1]. Sometimes, recognizing ignorance is a requirement for pursuing knowledge. Customer insight is a vital concept for marketers to explore customer's potential needs and wants. It's a hiding place people don't know or to be excavated by various methods. Its main purpose is to understand consumers' underlying mindsets, moods, motivation, desires, aspirations, and motivates that trigger their attitude and actions. A more precisely definition of customer insight by Laughlin as "a non-obvious understanding about your customers, which if acted upon, has the potential to change their behavior for mutual benefit” [12]. As major development in big data, obtaining and analyzing 
complex information become a main function for organizations to exploit the place people don't know to increase customer value. Firestein suggested that big data enables marketers to realize new gaps or areas of ignorance in marketers 'understanding of consumer behavior [13]. Southwest Airlines uses big data to deliver excellent customer service. Big data, changed their way to work, has become a strategic tool to improve their service. The airline company uses a speech-analytics tool, which is to records conversations between services personnel and consumers to extract insights that can improve the performance of service personnel. Meanwhile, Southwest Airlines set up the speech-analytics software to extract consumer insights and train its service personnel. Southwest is using insights from big data to meet unrecognized consumer needs. Moreover, as soon as use, analyze, manage and process big data appropriately, it is possible to propose innovative and actionable insights for business.

\section{Prediction of Big Data}

Big data creates more value via predicting consumer behavior before competitors even customers themselves. Target utilizes consumer insights from big data to predict customers 'needs and wants. Based on big data they have, Target enables their marketers to estimate whether a female shopper is pregnant and her due date before competitors or even women's family knows of her pregnancy. Target makes good advantage of predictive data to influence customer's purchases for baby items before competitor. With the increase of data, marketing practitioners are able to advance their understanding of consumer behavior. Thus, Target can achieve the sustainable competitive advantages.

Aside from predicting customer behavior, some researches prove that big data is helping company to customize our online experience and shepherding people through the internet. Today's business applications are raking in mountains of new customer, market, social listening, and real-time app, cloud, or product performance data. Predictive marketing is used by a lot of companies who have tremendous data to leverage all of that information, gain tangible new insights, and stay ahead of the competition. The population of Chinese people born between 1995 and 2016 has reached 378 million, accounting for 27 percent of China's total population. These people, who are called Generation Z or the post-1995 generation, have demonstrated strong consumer power. The data generated from these consumers are huge and complex. Tmall, which is a leading platform for online trade in China, benefits from their big dataset. Tmall collects as much data as possible to analyze their consumers. In recent year, Tmall has launched "precision marketing." In big data era, instead of a group of people, precision marketing divides every individual shopper as a market segmentation, and plans marketing strategy for every shopper differently. For example, if a shopper browses a product, big data system records and analyzes this information, and then services product or push relative advertisement related to the products the shopper browsed before when the shopper logs in app next time. Making full use of the historical data, carrying out precision marketing, and striving to improve repurchase rates and revisit rates of regular customers. With the widespread use of location-based services (LBS) that can offers users personalized information in a specific location at a specific time, customers can get advertisements or product recommendations based on their current location or predicted future position. An increased understanding of consumers' perceptions regarding personalized communication allows mobile marketers to better understand consumer needs and improve their campaign outcomes.

\section{The Challenges of Big Data}

New technologies allow computers, smartphones even social media become immense storage areas for personal information. Modern marketers have the capability to gather all information to 
form customer profiles for targeting individuals narrowly. However, over the past few years, negative attitudes toward data sharing and promotion personalization from different platforms have spread among U.S. consumers. The much big data be used, the more challenges it faces. The challenges related to big data were identified by Sivarajah et al. who argue challenges are the group of challenges concerning to the characteristics of the data itself [7]. Large scale and the volume of data is a challenging task for practitioners to process and analyze. Data is captured in diverse form and different sources, so it is a tough task to comprehend and manage such data. The challenge of velocity is from the requirement to manage the high influx rate of heterogeneous data.

Privacy and security are major threatening people. It is found that large amounts of Facebook data were used in attempts to influence the US election. As reported by news, Cambridge Analytica hired by the Trump campaign get its hands on around 87 million Facebook profiles to create targeted pro-Trump messages. The Facebook data privacy scandal flooding the news for the past couple of months is part of a broader movement against big corporations control over data. It is unclear how much impact the data actually played in these events. Customers are worried about the negative impacts of the data sharing will encounter. For example, customers can be identified by location-based service providers. The location information probably links to residential information, which is quite private information for people. Protection for privacy is an urgent issue for big data users. Machanavaijhala and Reiter declared that it is illegal to fail to protect citizen's privacy and open their information to non-governmental sectors[14]. Meanwhile, security is identified as another big challenge for big data by some researchers. Just like traditional data, big data is equally vulnerable to attack [3]. For data security, the threats from malware is growing and big data will be unacceptable globally if security issue is not addressed appropriately. Therefore, the security control to ensure is no time to delay. The data collators and users should do their utmost to protect the privacy of security of citizens who are willing to offer their information to make great contribution for marketing analysis.

\section{Conclusion}

The sheer volume of data applied by organizations via modern technology and internet is growing at tremendous rate. More and more researchers and marketing practitioners pay much attention to the application of big data. There are a lot of strong evidences that marketing performance can be improved through big data related to products, price, promotion and place. Big data and big data analytics support data-driven decisions allowing making decision timely and efficiently. Besides assisting marketing strategies, big data is playing a crucial role in obtaining customer insights, predicting customer behavior and marketing precisely. Nevertheless, big data poses challenges unavoidably. Its characteristics are data challenges in the road of analyzing, processing. In the matter of management of data, the privacy and security issues have taken place in the world are threatening people. Besides utilizing big data adequately, the further application of big data needs to balance the benefits from big data and the negative issues from big data.

\section{Acknowledgement}

This is the project supported by the Office for Education Sciences Planning of Fujian Province. The project name is 'The research on the talents training mode of big data marketing innovation and entrepreneurship in the new era of information’. The program code is FBJG20170207.

\section{References}

[1] Erevelles, S., Fukawa, N. and Swayne, L. (2016) Journal of Business Research, 69, 897-904. 
[2] Tellis, G.J., Prabhu, J.C. and Chandy, R.K. (2009) The Journal of Marketing, 73, 3-23.

[3] Yi, X., Liu, F., Liu, J. and Jin, H. (2014) IEEE Network, 28, 5-13.

[4] Berners-Lee, T., Shadbolt, N. (2011) The Times, 1.

[5] Provost, F., Fawcett, T. (2013) Big Data, 1, 51.

[6] Fusfeld, A. (2010) The digital 100: the world's most valuable startups. Bus Insider, Sep. 23.

[7] Sivarajah, U., Kamal, M.M., Irani, Z. and Weerakkody, (2017) Journal of Business Research, 70, 263-286.

[8] Kambatla, K., Kollias, G., Kumar, V. and Grama, A. (2014) Journal of Parallel \& Distributed Computing, 74, 2561-2573.

[9] Brynjolfsson, E., Hitt, L.M. and Kim, H.H. (2011) Social Science Electronic Publishing, 1.

[10] Satell, G. (2014). 5 things managers should know about the big data economy. Forbes, Feb. 26.

[11] Story, V., O'Malley, L. and Har, S. (2011) Industrial Marketing Management, 40, 952-966.

[12] Laughlin, P. (2014) Journal of Direct Data \& Digital Marketing Practice, 16, 75-79.

[13] Firestein, S. (2012). Ignorance: How it drives science. New York: Oxford University Press.

[14] Machanavajjhala A., Reiter, J.P. (2012) The ACM Magazine for Students, 19, 20-23. 